\title{
Corticosteroid treatment and prognosis in pulmonary eosinophilia
}

\author{
S CAPEWELL, B J CHAPMAN, F ALEXANDER, A P GREENING, G K CROMPTON \\ From the Respiratory Unit, Northern General Hospital, Edinburgh, and the Medical Computing and Statistics \\ Unit, University of Edinburgh
}

ABSTRACT The acute and long term responses to corticosteroid treatment in 65 patients with pulmonary eosinophilia have been reviewed. Of the 247 episodes of pulmonary eosinophilia that were documented during a median follow up period of 14 years, 186 were treated with prednisolone. Complete clearing of chest radiographic infiltrates occurred in $65 \%$ of the 247 episodes, partial clearing in $25 \%$, and no response in $9 \%$. Blood eosinophil counts were monitored during 194 episodes and returned to normal in $72 \%$, decreased in $19 \%$, and remained raised in $9 \%$. Complete radiological clearing and a reduction in blood eosinophil counts were more common in episodes treated with prednisolone. Long term prednisolone was given to 28 of the 33 patients with allergic bronchopulmonary aspergillosis (mean $7.4 \mathrm{mg} /$ day for 11 years) and to 29 of the 32 "non-aspergillosis" patients (mean $8.1 \mathrm{mg}$ /day for 4.6 years). Initial pulmonary function, measured between episodes, was worse in patients with allergic aspergillosis than in those without (mean \% predicted: $\mathrm{FEV}_{1} 57 \% v 83 \%$, vital capacity (VC) $76 \% v 88 \%$ ). During a mean follow up period of 12 years neither group displayed further decline in $\mathrm{FEV}_{1}$ or VC.

\section{Introduction}

Corticosteroids have been used in the treatment of pulmonary eosinophilia for over 20 years. ${ }^{12}$ Although recommended for acute episodes, ${ }^{23}$ the value of long term treatment remains the subject of much debate. Pulmonary eosinophilia tends to recur, particularly when associated with allergic bronchopulmonary aspergillosis, and permanent lung damage with pulmonary fibrosis or proximal bronchiectasis or both often results. ${ }^{16}$ Antifungal agents, including natamycin, nystatin, and clotrimazole, have been used but none, with the possible exception of ketoconazole, has proved effective. ${ }^{4-11}$ Inhaled corticosteroids and sodium cromoglycate improve the symptoms of chronic asthma but they do not suppress episodes of pulmonary eosinophilia in patients with allergic bronchopulmonary aspergillosis and may indeed mask them..$^{3412}$ Long term treatment with systemic corticosteroids has been advocated to prevent or reduce progressive lung damage from pulmonary eosinophilia but this has been on the basis of retrospective data, often from patients selected by virtue of secon-

Address for reprint requests: Dr G K Crompton, Respiratory Unit, Northern General Hospital, Edinburgh, EH5 2DQ.

Accepted 14 August 1989 dary or tertiary referral to a specialist centre. Recommended doses of long term prednisolone have varied widely-from $7.5 \mathrm{mg}$ to $15 \mathrm{mg}$ or more. ${ }^{458}$ The risks associated with long term corticosteroid treatment, however, are substantial. ${ }^{13}$ The long term prognosis of patients with pulmonary eosinophilia with and without allergic bronchopulmonary aspergillosis is not clear. We have therefore reviewed corticosteroid treatment, clinical response and long term prognosis in 65 patients with pulmonary eosinophilia seen in a single primary referral respiratory unit.

\section{Methods}

\section{PATIENTS}

Sixty five patients with pulmonary eosinophilia attending the Northern General Hospital, Edinburgh, during 1966-86 were identified by means of a disease based card index system. All had evidence of transient pulmonary shadowing associated with a peripheral blood eosinophil count exceeding $500 \times 10^{6} / 1$. The patient's medical records were reviewed with particular reference to evidence of asthma, atopy, hypersensitivity to Aspergillus fumigatus, clinical features associated with episodes of pulmonary eosinophilia, results of pulmonary function tests, corticosteroid treatment, and radiographic features. Patients with aspergilloma (mycetoma) were excluded. The 
method of identifying A fumigatus precipitins is described and definition given of asthma and atopy and of radiological evidence of fibrosis and bronchiectasis in the accompanying article. ${ }^{6} \mathrm{~A}$ diagnosis of allergic bronchopulmonary aspergillosis was made if an immediate skinprick test response to $A$ fumigatus was positive and if serum precipitins to $A$ fumigatus were present or $A$ fumigatus was cultured from sputum.

\section{INVESTIGATIONS}

\section{Pulmonary eosinophilia}

An episode of pulmonary eosinophilia was defined as new radiographic pulmonary shadowing associated with a peripheral blood eosinophil count exceeding $500 \times 10^{6} / 1$. The response to corticosteroid treatment of individual episodes of pulmonary eosinophilia was assessed clinically, haematologically, and radiologically. Clearing of chest radiographic shadowing within one month was graded as "complete," "partial," or "none," and resolution of peripheral blood eosinophilia was graded as "complete" $(<500 \times$ $\left.10^{6} / 1\right)$, "partial" $\left(\geqslant 500 \times 10^{6} / 1\right.$ but significantly reduced from peak value), or "none."

\section{Pulmonary function}

Spirometry was performed in each patient both during and between episodes of pulmonary eosinophilia. The initial forced expiratory volume in one second $\left(F_{E V}\right)$ and vital capacity (VC) were taken as the best of the first three values recorded between episodes in each patient within a year of presentation. Follow up FEV and VC in each patient were defined as the best of the last three measurements recorded during the last 12 months of follow up. Measurements for each patient were standardised as percentages of predicted values. ${ }^{14}$

Results were analysed by the $\chi^{2}$ test with Yates's correction and Wilcoxon's rank sum test for unpaired data. $^{15}$

\section{Results}

Sixty five patients ( 27 men and 38 women) with pulmonary eosinophilia were identified. Their median age was 39 years at the time of their first episode. Two hundred and forty seven episodes of pulmonary eosinophilia were recorded during a median follow up period of 14 (range 1-31) years. Eighteen patients had single and 47 recurrent episodes. Thirty three met the criteria for allergic bronchopulmonary aspergillosis; the remaining 32 were categorised as "non-aspergillosis."

\section{TREATMENT FOR ACUTE EPISODES OF}

\section{PULMONARY EOSINOPHILIA}

Prednisolone was given for $186(75 \%)$ of the 247 episodes, either as a short course or as a major dosage increase (10 $\mathrm{mg}$ or more) above the maintenance dose.
Sixty episodes $(32 \%)$ were treated with an initial daily dose of 5-15 mg, $86(46 \%)$ with $20 \mathrm{mg}$, and $40(21 \%)$ with over $20 \mathrm{mg} /$ day. The proportion of episodes음 treated with prednisolone increased from $1960 \frac{\text { क }}{\circ}$ onwards. (40-50\% of episodes before $1965,80-90 \% \stackrel{\triangle}{\circ}$ since 1980). Although symptomatic improvement was usually rapid, this proved difficult to quantify retrospectively. Response was therefore assessed in terms ${ }_{-}^{\circ}$ of clearing of chest radiographic abnormalities and $\vec{\omega}$ resolution of peripheral blood eosinophilia.

RADIOGRAPHIC RESPONSES TO PREDNISOLONE Complete clearing of the radiographic abnormalities occurred in 129 of the $186(70 \%)$ episodes treated with prednisolone compared with only 17 of the $59(29 \%) \mathrm{N}$ episodes not treated with prednisolone $(p<0.001) 6$ (fig 1). There were no differences between the radiological responses in patients with and without allergic bronchopulmonary aspergillosis.

\section{BLOOD EOSINOPHILIA RESPONSES TO \\ PREDNISOLONE}

Blood eosinophil counts were recorded sequentially in $\vec{\varnothing}$ 194 of the 247 episodes. Eosinophil counts returned toce normal in $117(76 \%)$ of 153 episodes treated witho prednisolone compared with only $15(37 \%)$ of 41 乏 episodes not treated with corticosteroids $(\mathrm{p}<0.001)$ (fig 2). The blood eosinophil count fell in all but six of 153 episodes $(96 \%)$ treated with prednisolone com-ब, pared with 24 of 41 episodes (59\%) not treated with prednisolone. Complete resolution of eosinophilia was을 more common with higher doses of prednisolone (fig 2). There were no significant differences in blood eosinophil responses in patients with and without allergic bronchopulmonary aspergillosis.

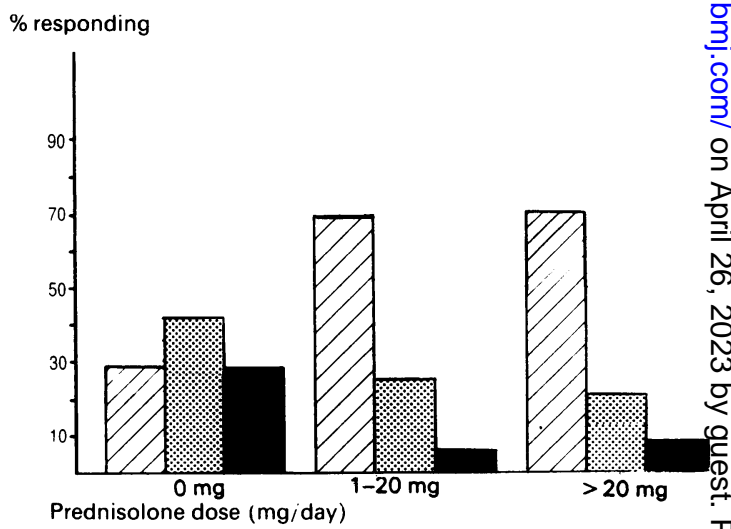

Fig 1 Clearing of chest radiographic infiltrates during episodes of pulmonary eosinophilia according to dose of prednisolone. Complete radiographic response; partial response; no response. 


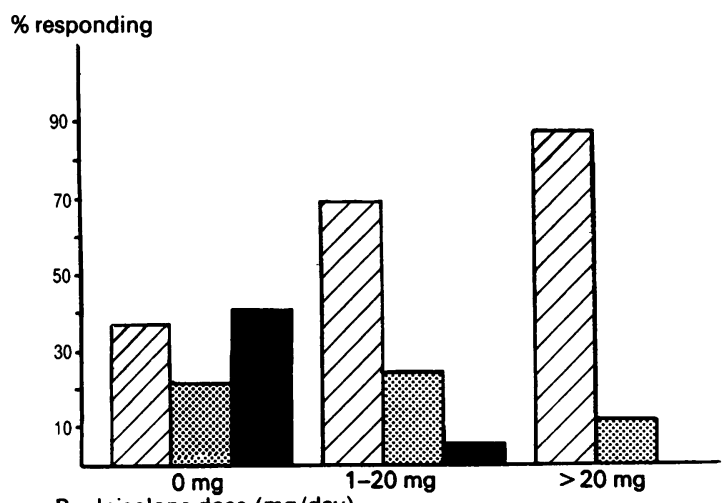

Prednisolone dose (mg/day)

Fig 2 Resolution of peripheral blood eosinophilia during episodes of pulmonary eosinophilia according to dose of prednisolone. $\square$ Complete radiographic response; partial response; no response.

\section{COMPARISON OF THE CLEARING OF CHEST} RADIOGRAPH ABNORMALITIES AND THE BLOOD EOSINOPHILIA RESPONSE

The degree of clearing of the radiological abnormalities was associated with decrease in blood eosinophil counts. Of 153 episodes treated with prednisolone, complete clearing of the radiograph and return of blood eosinophil counts to normal values were seen in $90(59 \%)$, a partial response in both in nine $(6 \%)$, and persistent radiographic abnormality and eosinophilia in only two (1\%) (table 1). Persistent radiographic shadowing with complete resolution of the eosinophilia occurred in 29 and persistent eosinophilia with radiographic clearing in 19 (table 1). In contrast, of the 41 episodes not treated with prednisolone, only nine showed complete clearing of the radiograph and complete loss of eosinophilia $(p<0.001)$ (table 1); eight had persistent eosinophilia and radiographic shadowing.

\section{LONG TERM PREDNISOLONE TREATMENT}

Of the total of 247 episodes of pulmonary eosinophilia, 182 were recurrences occurring in 47 patients. Ninety $(49 \%)$ recurred in patients not receiving long term prednisolone treatment, $82(45 \%)$ during prednisolone treatment with a daily dose of $10 \mathrm{mg}$ or less, and $10(6 \%)$ with a dose exceeding $10 \mathrm{mg}$ daily.

Twenty eight of the 33 patients with allergic bronchopulmonary aspergillosis were treated with long term prednisolone in a mean (SD) daily dose of $7.4(1.7) \mathrm{mg}$ for a mean period of 11 years; the mean follow up was $18(7 \cdot 7)$ years. Twenty nine of the 32 "non-aspergillosis" patients received long-term prednisolone in a mean daily dose of $8 \cdot 1(4 \cdot 1) \mathrm{mg}$ for a mean period of $4.6(4.9)$ years; the mean follow up was $9.6(7 \cdot 7)$ years.
Table 1 Clearance of radiological shadows and resolution of blood eosinophilia

\begin{tabular}{|c|c|c|c|}
\hline \multirow{2}{*}{$\begin{array}{l}\text { Resolution of blood } \\
\text { eosinophilia }\end{array}$} & \multicolumn{3}{|c|}{ Clearance of chest radiograph ( $\mathrm{No}(\%))$} \\
\hline & Complete & Partial & None \\
\hline \multicolumn{4}{|c|}{153 episodes treated with prednisolone } \\
\hline $\begin{array}{l}\text { Complete } \\
\text { Partial } \\
\text { None }\end{array}$ & $\begin{array}{c}90(59) \\
17(11) \\
2(1)\end{array}$ & $\begin{array}{c}21(14) \\
9(6) \\
2(1)\end{array}$ & $\begin{array}{l}8(5) \\
3(2) \\
2(1)\end{array}$ \\
\hline \multicolumn{4}{|c|}{41 episodes not treated with prednisolone } \\
\hline $\begin{array}{l}\text { Complete } \\
\text { Partial } \\
\text { None }\end{array}$ & $\begin{array}{l}9(22) \\
0 \\
1(2)\end{array}$ & $\begin{array}{l}2(5) \\
7(17) \\
8(19)\end{array}$ & $\begin{array}{l}4(10) \\
2(5) \\
8(19)\end{array}$ \\
\hline
\end{tabular}

\section{SPIROMETRY}

Fifty one of the 65 patients had been followed up for sufficient time to calculate change in $\mathrm{FEV}_{1}$ and VC. In 26 patients with allergic bronchopulmonary aspergillosis, mean initial $\mathrm{FEV}_{1}$, measured between episodes of pulmonary eosinophilia, was lower than that of the 25 "non-aspergillosis" patients $(57 \% v 83 \%$ predicted; $\mathrm{p}<0.001)$; initial VC values did not differ significantly (76\% v 88\%;) (table 2 ). In the 26 patients with allergic bronchopulmonary aspergillosis spirometry was performed after a mean time interval of 14.4 years after the initial measurements (range 2-23.5 years). The corresponding interval in the 25 "non-aspergillosis" patients was $9 \cdot 5$ (range $2 \cdot 1-24 \cdot 5$ ) years. There was no significant decline in $\mathrm{FEV}_{1}$ or $\mathrm{VC}$ in either group. Mean FEV, remained significantly lower in the allergic bronchopulmonary aspergillosis group ( $\mathrm{p}<$ 0.001 ) (table 2).

\section{ahRADIOLOGICAL OUTCOME}

Bronchiectasis was thought to be present in 20 of the 33 patients with allergic bronchopulmonary aspergillosis compared with seven of the 32 "non-aspergillosis" patients ( $\mathrm{p}<0.005) .^{6}$ Twenty two of the 27

Table 2 Pulmonary function in subgroups of patients with pulmonary eosinophilia (mean (SD) \% predicted values)

\begin{tabular}{|c|c|c|c|}
\hline & Initial & Follow up & $\begin{array}{l}\text { Mean duration } \\
\text { of follow up } \\
\text { (years) }\end{array}$ \\
\hline $\begin{array}{l}F E V_{1} \\
\text { ABPA }(n=26) \\
\text { Non-ABPA }\end{array}$ & $\begin{array}{l}57^{* *}(20) \\
83^{* *}(26)\end{array}$ & $\begin{array}{l}61^{* *}(22) \\
79^{* *}(30)\end{array}$ & $\begin{array}{r}14 \cdot 4 \\
9 \cdot 5\end{array}$ \\
\hline $\begin{array}{l}\text { Fibrosis or bronchiectasis* } \\
(n=16)\end{array}$ & $53 * *(16)$ & $45(16)$ & $13 \cdot 1$ \\
\hline $\begin{array}{l}\text { Without fibrosis or } \\
\text { bronchiectasis* }\end{array}$ & $80 * *(30)$ & $80(35)$ & $11 \cdot 5$ \\
\hline $\begin{array}{l}\text { Vital capacity } \\
\text { ABPA } \\
\text { Non-ABPA }\end{array}$ & $\begin{array}{l}76(22) \\
88(21)\end{array}$ & $\begin{array}{l}81(21) \\
86(22)\end{array}$ & $\begin{array}{r}14 \cdot 4 \\
9 \cdot 5\end{array}$ \\
\hline $\begin{array}{l}\text { Fibrosis or } \\
\text { bronchiectasis* } \\
\text { Without fibrosis or }\end{array}$ & $69 * *(14)$ & $71(14)$ & $13 \cdot 1$ \\
\hline bronchiectasis* & $91^{* *}(25)$ & $93(29)$ & $11 \cdot 5$ \\
\hline
\end{tabular}

* As assessed by chest radiograph

$* *$ p $<0.001$.

ABPA-allergic bronchopulmonary aspergillosis. 
patients with radiographic changes suggesting fibrosis or bronchiectasis had developed persistent radiological abnormalities before starting long term prednisolone treatment and 12 before any prednisolone treatment. The development of changes suggesting fibrosis or bronchiectasis was not related to the mean long term, daily dose of prednisolone or the duration of treatment. Only three patients developed new persistent radiological changes during long term corticosteroid treatment.

\section{Discussion}

This study represents one of the largest retrospective series of patients with pulmonary eosinophilia, with a total follow up of 897 patient years. The data support the value of corticosteroid treatment for episodes of pulmonary eosinophilia, ${ }^{1-316}$ as prednisolone treatment resulted in improved clearance of chest radiographic abnormalities and reduction of blood eosinophil counts. ${ }^{17-19}$ A steroid dose effect was observed, prednisolone in excess of $20 \mathrm{mg}$ a day producing resolution of blood eosinophilia and complete clearing of abnormalities on the chest radiograph more often than lower doses. Steroid response was equally good in patients with and without allergic bronchopulmonary aspergillosis. Radiographic clearing sometimes occurred in the absence of steroid treatment, as previously described. ${ }^{34}$

Pulmonary eosinophilia associated with allergic bronchopulmonary aspergillosis has been reported to have a worse prognosis than cryptogenic pulmonary eosinophilia, ${ }^{19-21}$ in terms both of pulmonary function and of radiological damage. ${ }^{4818223}$ In our series the patients with allergic bronchopulmonary aspergillosis already had lower FEV , values than those without aspergillosis at the time of clinical presentation. Radiological changes suggesting fibrosis or bronchiectasis were also already present at the time of presentation in many of the patients with allergic bronchopulmonary aspergillosis. Furthermore, during the period of follow up persistent radiological changes developed more often in the allergic bronchopulmonary aspergillosis group than in the nonaspergillosis group $(9 / 33 \vee 4 / 32)$. In the patients receiving long term prednisolone treatment such changes occurred in only three, all with allergic bronchopulmonary aspergillosis.

Long term corticosteroid treatment for pulmonary eosinophilia was advocated in the belief that it could prevent recurrent episodes and subsequent lung damage. ${ }^{14}$ Although daily doses of $7.5 \mathrm{mg}$ and $10 \mathrm{mg}$ have been advocated, these were based on retrospective reviews of selected groups of patients. ${ }^{48}$ The rationale for long term prednisolone treatment has been somewhat ambiguous and the drug has often
Capewell, Chapman, Alexander, Greening, Crompton: been given for control of symptoms of asthma rather than for the prevention of pulmonary eosinophilia. ${ }^{48} \mathrm{C}$ Patterson and colleagues recently recommended up to $\underline{\bar{E}}$ $40 \mathrm{mg}$ prednisolone a day initially, to be tailed off after $\frac{\overline{\bar{p}}}{\overline{0}}$ three to six months. ${ }^{5724}$ Half the recurrent episodes $\stackrel{\varnothing}{\varnothing}$ recorded in our patients, however, occurred while they were having long term prednisolone treatment, as has been recognised previously. ${ }^{41217}$ Many episodes of pulmonary eosinophilia are asymptomatic and may $\vec{\omega}$ therefore go undetected unless a chest radiograph is $\stackrel{\omega}{\circ}$ taken by chance. ${ }^{3412}$ In the absence of a chest $\vec{x}$ radiograph symptomatic episodes of pulmonary eosinophilia may be inappropriately treated as an exacerbation of asthma or bronchial infection.

Long term corticosteroid treatment with doses exceeding $5 \mathrm{mg}$ a day frequently produces major side ${ }^{\mathrm{T}}$ effects $^{413}$ and should therefore not be entertained lightly. A therapeutic nihilist might therefore use the $\vec{Z}$ data from our patients as evidence against long term prednisolone treatment. In contrast, the enthusiast $\Phi$ could argue that much of the permanent radiographic 3 abnormality and impaired pulmonary function had $\stackrel{\Phi}{-}$ occurred before any steroid treatment. Furthermore, $\vec{\bullet}$ the development of new persistent radiological changes in only three patients after the start of long term. prednisolone treatment and the lack of further decline 0 in pulmonary function might both reflect benefit of treatment. Neither conclusion can be fully justified by retrospective data from Edinburgh or elsewhere. We suggest that prospective studies are urgently needed. ${ }^{523} \stackrel{\mathbb{Q}}{\longrightarrow}$ We thank Dr R Gibson and the clerical staff of the $\frac{\overrightarrow{\vec{O}}}{3}$ respiratory unit for their help and Miss J Holywell for typing the manuscript.

\section{References}

1 Henderson AH, Pearson JEG. Treatment of bronchopulmonary aspergillosis with observations on the use of natamycin. Thorax 1968;23:519-23.

2 McCarthy DS, Pepys J. Allergic bronchopulmonary윽 aspergillosis. Clinical immunology: (1) Clinical features. Clin Allergy 1971;1:261-86.

3 Schuyler MR. Allergic bronchopulmonary aspergillosis. Clin Chest Med 1983;4:15-22.

4 Safirstein BH, D'Souza MF, Simon G, Tai EH-C, Pepys J. Five year follow-up of allergic bronchopulmonary aspergillosis. Am Rev Respir Dis 1973;108:450-9.

5 Patterson R, Greenberger PA, Halwig M, Liotta JL, Roberts M. Allergic bronchopulmonary aspergillosis:o

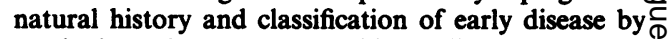
serologic and roentgenographic studies. Arch Intern $\stackrel{9}{?}$ Med 1986;146:916-8.

6 Chapman BJ, Capewell S, Gibson R, Greening AP, ${ }^{\circ}$ Crompton GK. Pulmonary eosinophilia with and $\overrightarrow{\mathbb{D}}$ without allergic bronchopulmonary aspergillosis. $\frac{?}{\square}$ Thorax 1989;44:919-24. 
7 Crompton GK, Milne LJR. Treatment of bronchopulmonary aspergillosis with clotrimazole. $\mathrm{Br} J$ Dis Chest 1973;67:301-8.

8 Middleton WC, Paterson IC, Grant IWB, Douglas AC. Asthmatic pulmonary eosinophilia: a review of 65 cases. Br J Dis Chest 1977;71:115-22.

9 Shale DJ, Faux JA, Lane DJ. Trial of ketoconazole in non-invasive pulmonary aspergillosis. Thorax 1987; 42:26-31.

10 Currie DC, Harvey C, Longbottom JC, Darbyshire JH, Nunn AJ, Cole PJ. A controlled trial of natamycin in treatment of allergic bronchopulmonary aspergillosis [abstract]. Thorax 1988;43:860P.

11 Hay RJ. Recent advances in the management of fungal infections. $Q J$ Med 1987;64:631-9.

12 Crompton GK, Research Committee of the British Thoracic Association. Inhaled beclomethasone dipropionate in allergic bronchopulmonary aspergillosis. Report to Research Committee of British Thoracic Association. Br J Dis Chest 1979;73:349-56.

13 Kwong FK, Sue MA, Klaustermeyer WB. Corticosteroid complications in respiratory disease. Ann Allergy 1987;58:326-30.

14 Cotes JE. Lung function: principles and application in medicine. 4th ed. Oxford: Blackwell Scientific Publications, 1979.

15 Armitage P. Statistical methods in medical research. Oxford: Blackwell Scientific Publications, 1971.
16 Jordan MC, Bierman CW, Van Ardsdal PP. Allergic bronchopulmonary aspergillosis. Ann Intern Med 1971;128:576-9.

17 Rosenberg M, Patterson R, Roberts M, Wang J. The assessment of immunologic and clinical changes occurring during corticosteroid therapy for allergic bronchopulmonary aspergillosis. Am J Med 1978; 64:599-606.

18 Malo JL, Pepys J, Simon G. Studies in chronic allergic bronchopulmonary aspergillosis. 2-Radiological findings. Thorax 1977;32:269-74.

19 McCarthy DS, Simon G, Hargreave FE. The radiological appearances in allergic bronchopulmonary aspergillosis. Clin Radiol 1970;21:366-75.

20 McCarthy DS, Pepys J. Cryptogenic pulmonary eosinophilia. Clin Allergy 1973;3:339-51.

21 Turner-Warwick M, Assem ESK, Lockwood M. Cryptogenic pulmonary eosinophilia. Clin Allergy 1976;6:135-45.

22 Scadding JG. Eosinophilic infiltrations of the lung in asthmatics. Proc $R$ Soc Med 1971;64:381-92.

23 Malo JL, Hawkins R, Pepys J. Studies in chronic allergic bronchopulmonary aspergillosis-clinical and immunological findings. Thorax 1977;32:254-61.

24 Patterson R, Greenberger PA, Radin RC, Roberts M. Allergic bronchopulmonary aspergillosis: Staging as an aid to management. Ann Intern Med 1982;96: 286-91. 